\title{
The role of genetic diversity in the evolution and maintenance of environmentally-cued, male alternative reproductive tactics
}

\author{
K. A. Stewart ${ }^{1 * \dagger} \mathbb{D}$, R. Draaijer ${ }^{1 \dagger}$, M. R. Kolasa ${ }^{2}$ and I. M. Smallegange ${ }^{1}$
}

\begin{abstract}
Background: Alternative reproductive tactics (ARTs) are taxonomically pervasive strategies adopted by individuals to maximize reproductive success within populations. Even for conditionally-dependent traits, consensus postulates most ARTs involve both genetic and environmental interactions (GEIs), but to date, quantifying genetic variation underlying the threshold disposing an individual to switch phenotypes in response to an environmental cue has been a difficult undertaking. Our study aims to investigate the origins and maintenance of ARTs within environmentally disparate populations of the microscopic bulb mite, Rhizoglyphus robini, that express 'fighter' and 'scrambler' male morphs mediated by a complex combination of environmental and genetic factors.
\end{abstract}

Results: Using never-before-published individual genetic profiling, we found all individuals across populations are highly inbred with the exception of scrambler males in stressed environments. In fact within the poor environment, scrambler males and females showed no significant difference in genetic differentiation (Fst) compared to all other comparisons, and although fighters were highly divergent from the rest of the population in both poor or rich environments (e.g., Fst, STRUCTURE), fighters demonstrated approximately three times less genetic divergence from the population in poor environments. AMOVA analyses further corroborated significant genetic differentiation across subpopulations, between morphs and sexes, and among subpopulations within each environment.

Conclusion: Our study provides new insights into the origin of ARTs in the bulb mite, highlighting the importance of GEls: genetic correlations, epistatic interactions, and sex-specific inbreeding depression across environmental stressors. Asymmetric reproductive output, coupled with the purging of highly inbred individuals during environmental oscillations, also facilitates genetic variation within populations, despite evidence for strong directional selection. This cryptic genetic variation also conceivably facilitates stable population persistence even in the face of spatially or temporally unstable environmental challenges. Ultimately, understanding the genetic context that maintains thresholds, even for conditionally-dependent ARTs, will enhance our understanding of within population variation and our ability to predict responses to selection.

Keywords: Inbreeding depression, Epistasis, Genetic correlation, Environmental threshold model, Phenotypic plasticity, Conditional strategy

\footnotetext{
* Correspondence: stewart.a.kat@gmail.com

Stewart KA and Draaijer R declare equal first-author contribution.

${ }^{+}$K. A. Stewart and R. Draaijer contributed equally to this work.

${ }^{1}$ Department of Evolutionary and Population Biology, Institute for Biodiversity

and Ecosystem Dynamics, University of Amsterdam, PO Box 94240, 1090 GE

Amsterdam, The Netherlands

Full list of author information is available at the end of the article
}

C) The Author(s). 2019 Open Access This article is distributed under the terms of the Creative Commons Attribution 4.0 International License (http://creativecommons.org/licenses/by/4.0/), which permits unrestricted use, distribution, and reproduction in any medium, provided you give appropriate credit to the original author(s) and the source, provide a link to the Creative Commons license, and indicate if changes were made. The Creative Commons Public Domain Dedication waiver (http://creativecommons.org/publicdomain/zero/1.0/) applies to the data made available in this article, unless otherwise stated. 


\section{Background}

In numerous species, it is common for individuals (usually males) to adopt different strategies to increase their reproductive success when intrasexual competition is intense. These strategies can ultimately lead to diversity within populations, comprising of characteristics such as behaviour, physiology, or morphology [1]. Referred to as alternative reproductive tactics (ARTs), strategies such as these encompass trade-offs between increased reproductive potential versus the costs incurred to produce traits under selection, often leading to the development of a less energetically demanding tactic, such as sneakers (versus guards) or satellites (versus callers). Although taxonomically widespread and studied in various organisms [1], the proximate mechanisms responsible for ART trait evolution, or the processes that maintain ARTs within single populations, are not always well understood. Some ARTs are plastic by nature, driven by seemingly pure environmental effects (e.g., dung beetles, Onthophagus acuminatus; [2]), whereas others are fixed, determined exclusively by genetic underpinnings (e.g. lekking sandpiper, Philomachus pugnax; [3]), although the latter remains a relatively rarer phenomenon [4-6]. More commonly however, species demonstrating ARTs involve a combination of both genetic and environmental influences, that interrelate in genotype-by-environment interactions [7].

Genotype-by-environment interactions (GEIs) are routinely observed in traits linked to fitness [8] such that in different environments, numerous genotypes may display and switch superiority (ecological cross-over), assisting in the maintenance of variation within populations. Moreover, male sexually selected traits often show condition-dependence that is assumed to involve many loci, providing ample opportunity for mutations ('genic capture hypothesis' [9]) and genetic variation. For example, high genetic diversity (heterozygosity) has been linked to an individual's fitness and condition, including an increase in survival [10,11], parasite resistance [12], developmental stability [13], competitive ability [14], viability $[9,15,16]$, mating opportunities [17], and the expression of costly secondary sexually selected traits [18]. Together, GEIs and condition-linked genetic diversity may help to reconcile the origin and maintenance of ARTs within populations [19], despite presumably strong selective forces promoting the canalization of traits, and genetic erosion associated with sexual selection ('the lek paradox') $[19,20]$.

Currently, the environmental threshold model, which links condition-dependence and GEIs [21-23], is the most widely accepted process for ART expression. Specifically, this model posits that environmental circumstances experienced by an individual during ontogeny leads to an all-or-none response in terms of expressing ARTs, which in-turn is likely influenced by the organism's genetic background [23]. Male polymorphic variation is thus thought of as a threshold trait based on a continuously distributed phenotype that is environmentally sensitive [24]. Threshold traits have been shown to have a heritable basis, although more likely due to the heritability of the underlying threshold itself (liability traits) [25, 26]. If this polymorphic variation is under polygenic control, condition-linked genetic diversity likely plays an important role in trait expression. ARTs involve complex traits that can be heritable, subject to selection, and evolve, yet to date, the genetic basis underlying the evolution of conditionally-dependent ARTs has been difficult to quantify [27].

The bulb mite (Rhizoglyphus robini) is a microscopic agricultural pest, which thrives on invading crops and disperses easily when food is deprived (a species familiar with fluctuating environment conditions) [28]. This species demonstrates a short generation time, has high reproductive potential [29], and is easily reared in laboratory conditions, making it an ideal organism for experimental evolution studies. Intriguingly, the bulb mite demonstrates a complex ART system that has recently described up to three male polymorphisms, including a 'megascrambler' [30] that, due to its rareness within populations, will be excluded from the current study. Of the two prominent male ARTs in $R$. robini, individuals express either a 'fighter' or 'scrambler' mating tactic consisting of the ontogenetic development (or not) of weaponry comprised of a thickened, sharply terminated third pair of legs used to combat and kill rival males (fighters and scramblers, respectively) (Fig. 1). The environmental threshold model is a good candidate model to explain the evolution of this male dimorphism as high nutritional quality and quantity during development increases juvenile body size, which in-turn increases fighter morph expression in adulthood [31, 32]. An experimental test of this model's predictions on evolutionary shifts in ART expression indeed confirmed threshold shifts when selecting against fighter expression. This analysis, however, failed to capture the observed evolutionary threshold shifts when selecting against scrambler expression [33], likely because scrambler expression shifted evolutionarily in response to the demographic consequences of the experimental treatment, rather than the treatment itself. It therefore seems likely that multiple environmental drivers are involved to maintain this male dimorphism [34]. Previous research also demonstrates the bulb mite ART is somewhat heritable, yet these heritability scores vary widely depending on population or study, ranging between 0.18 to $>1.00$ based on experimental and modelling estimates [35-37], further suggesting this ART likely does not represents a simplistic environmental or genetic trigger.

Here, we aim to resolve broad evolutionary questions surrounding the origin and maintenance of ARTs by quantifying the cryptic variance underpinning threshold responses to environmental cues. We do this by testing the hypothesis that genetic diversity differs between the two male ARTs in the 


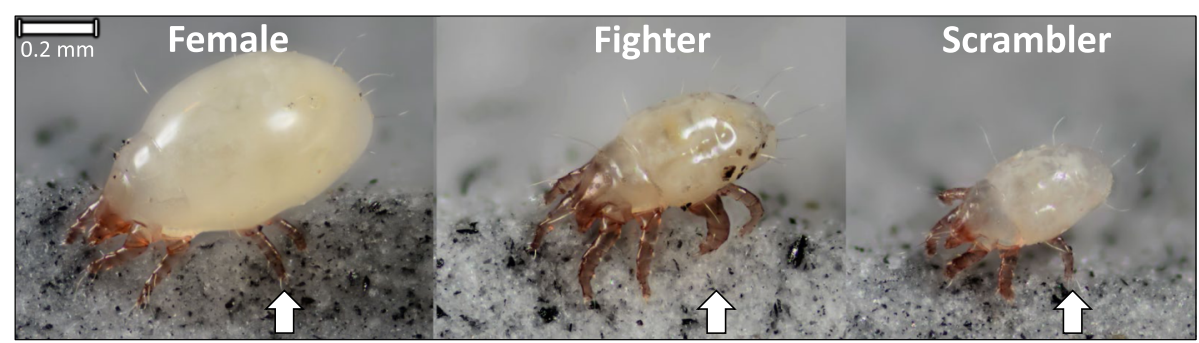

Fig. 1 Dorsolateral photographic images of adult bulb mites (Rhizoglyphus robini) including the female, and male ARTs (fighter, and scrambler). All individuals are presented at the same scale (scale bar: top left) and aligned from largest to smallest (left to right), with arrows indicating major structural differences in the third-leg pair among sexes and morphs. Photographs produced by Jan van Arkel, 2017

bulb mite, such that larger fighters with associative high body condition will demonstrate higher levels of genetic diversity compared to their smaller, poorer conditioned scrambler counterparts. Using populations consisting of tensof-thousands of individual bulb mites reared under different environments, we quantified underlying genetic context in relation to ART expression, using never-before-published genetic markers to quantify individual-level genetic diversity across populations.

\section{Materials \& methods}

\section{Specimen maintenance and collection}

We used bulb mites from stock populations originating from 10 sampling sites via collecting flower bulbs near Anna Paulowna, North Holland, Netherlands in 2010, that ultimately comprise tens-of-thousands of individuals. Mites were reared and maintained at the Institute for Biodiversity and Ecosystem Dynamics at the University of Amsterdam, Netherlands, in a controlled environmental chamber $\left(25 \pm 1{ }^{\circ} \mathrm{C}, 60 \%\right.$ relative humidity, 16:8 h light-dark photoperiod; sensu [38]) under two different rearing environments commonly used in life history studies to assess growth, development, and ART expression of mites from the family Acaridae (e.g., [39-41]). These two environments, henceforth be described as 'poor' or 'rich', differed only in their nutritional resources; mites were fed either rolled oats (poor food quality) or dried yeast (rich food quality via high quantity of protein), ad libitum. The rich resource treatment (yeast), in fact, creates a similar rearing environment to that of natural bulb mite populations feeding on garlic bulbs [39].

From the rich and poor environments, mites were randomly collected and examined with a stereomicroscope for identification. Sexes and ART morphs were identified according to the morphological criteria described by Smallegange [38], including size delimitation, genitalia, and the presence/absence of enlarged third leg pairs (main ART trait differentiation). Following recommendations that 20-30 individuals assayed within populations yield sufficiently reliable estimates for population genetic parameters [42], a total of 231 mites were sampled from the stock populations in both rich $(n=126)$ and poor $(n=105)$ environments, including 72 scrambler males (rich $n=42$, poor $n=30$ ), 76 fighter males (rich $n$ $=32$, poor $n=44$ ), and 83 females (rich $n=52$, poor $n=$ $31)$. Upon collection, mites were individually preserved in $1.5 \mathrm{~mL}$ Eppendorf tubes containing 95\% ethanol, and stored at $-20^{\circ} \mathrm{C}$ until DNA extraction.

Because we aimed to create near-equal sampling of each subpopulation (female, fighter, scrambler), the representative sex-ratio from the overall environments did not reflect the female biased operational sex-ratio from either stock or natural populations [33]. However, this sampling scheme should bear no influence on our interpretation of whether genetic context influences the expression of ARTs in the bulb mite system.

\section{DNA extraction, PCR amplification, and nSSR analysis}

Prior to extraction, all ethanol within the Eppendorf tubes was evaporated. For the female and fighter male mites, we used a modified protocol from Knegt et al. [43] in which chelex-based DNA extraction was performed: 4-5 zirconium beads, $50 \mu \mathrm{L}$ of a $5 \%$ chelex solution (Bio-Rad laboratories), and $5 \mu \mathrm{L}$ of proteinase $\mathrm{K}\left(20 \mathrm{mg} \mathrm{ml}^{-1}\right)$ were added to each tube, after which the samples were homogenized 3 times for 30s at $6500 \mathrm{rpm}$ using a Precellys 24 tissue homogenizer (Bertin Corp). Upon homogenization, the samples were incubated for $2 \mathrm{~h}$ at $56^{\circ} \mathrm{C}$, and proteinase $\mathrm{K}$ was inactivated via incubation for $8 \mathrm{~min}$ at $95^{\circ} \mathrm{C}$. Samples were centrifuged for $2 \mathrm{~min}$ at $14000 \mathrm{rpm}$ and thereafter stored at $-20^{\circ} \mathrm{C}$.

As scrambler male mites are typically much smaller than their fighter or female counterparts, we adjusted the DNA extraction protocol as follows: after the evaporation of all ethanol, $4.5 \mu \mathrm{L}$ proteinase $\mathrm{K}\left(20 \mathrm{mg} \mathrm{ml}^{-1}\right)$ was added to each Eppendorf tube, and with a pestle, mites were ground into small pieces after which $30 \mu \mathrm{L}$ of a $5 \%$ chelex solution was added to each tube. The samples were subsequently incubated for $3 \mathrm{~h}$ at $56^{\circ} \mathrm{C}$, and proteinase $\mathrm{K}$ was inactivated via incubation for $8 \mathrm{~min}$ at $95^{\circ} \mathrm{C}$. Samples were vortexed and centrifuged shortly, and stored at $-20^{\circ} \mathrm{C}$ prior to DNA amplification. 
In total we tested 16 nuclear simple sequence repeats (nSSR) primer pairs designed for our species at Jagiellonian University in Kraków [44], optimizing the primer pairs and concomitant PCR protocol for our own populations using Dreamtaq polymerase (Thermo Fisher Scientific). Each primer pair was amplified individually in $15 \mu \mathrm{L}$ reactions wherein each reaction contained $3 \mu \mathrm{L} 5$ $\times$ Dreamtaq buffer, $3 \mu \mathrm{L}$ dNTPs $(10 \mu \mathrm{M}), 0.5 \mu \mathrm{L} \mathrm{MgCl}_{2}$, $0.5 \mu \mathrm{L} \mathrm{BSA}$, forward and reverse primers (see Table 1 for concentrations), and $0.125 \mu \mathrm{L}$ Dreamtaq polymerase. Prior to adding DNA template, DNA samples were briefly vortexed and spun-down to separate the DNA solution from the chelex beads. To each sample, $2 \mu \mathrm{L}$ of DNA template was added. The thermal cycle protocol started at $95^{\circ} \mathrm{C}$ for $15 \mathrm{~min}$, followed by 35 cycles of denaturation at $94{ }^{\circ} \mathrm{C}$ for $30 \mathrm{~s}$, annealing at either $51^{\circ} \mathrm{C}$ or $53^{\circ} \mathrm{C}$ (see Table 1) for $90 \mathrm{~s}$, extension at $72^{\circ} \mathrm{C}$ for $90 \mathrm{~s}$, and a final extension at $72^{\circ} \mathrm{C}$ for $10 \mathrm{~min}$. PCR products were stored at $7{ }^{\circ} \mathrm{C}$ until analysis (within 1 week of extraction). Samples were visually inspected using $2 \%$ agarose gel electrophoresis before fragmentation analysis.

Primer pairs were labelled with four different fluorescent tags, allowing them to be multiplexed and analysed simultaneously using capillary electrophoresis (ABI PRISM 3100 Genetic Analyzer, Applied Biosystems). Per two amplicons (differently labelled), $1 \mu \mathrm{L}$ of PCR product, $0.3 \mu \mathrm{L}$ of orange dye labelled GeneScan ${ }^{\mathrm{Tw}}$ size standard 500LIZ ${ }^{\mathrm{mm}}$ (Applied Biosystems), and $10 \mu \mathrm{L}$ formamide was added and denatured before running on the ABI analyzer. Data was visualised, and alleles scored, in GeneMapper $^{\mathrm{Tm}}$ software (v4.1.1) (Applied Biosystems), after which each automatically scored allele was double-checked by hand. Our nSSRs were defined by a characteristic stutter followed by a peak of at least 450 relative fluorescent units or greater. We further assayed approximately $10 \%$ of our samples a second time to check and ensure repeatability of scoring.

\section{Statistical analyses}

With the use of GenoDive v.2.28 [45] that accounts for information gaps by drawing random alleles from the baseline allele frequencies (e.g., missing or null alleles, ensuring no individuals were excluded from analysis), various metrics of genetic diversity were calculated. Beyond calculating the number of alleles per locus $\left(\mathrm{n}_{\mathrm{A}}\right)$, we also quantified observed heterozygotes within a subpopulation (i.e., females, fighters, scramblers) $\left(\mathrm{H}_{\mathrm{O}}\right)$ and expected frequency of heterozygotes $\left(\mathrm{H}_{\mathrm{S}}\right)$ under Hardy-Weinberg equilibrium (HWE) [46], both ranging from 0 to 1 . These metrics were then used to calculate the inbreeding coefficient $\left(\mathrm{G}_{\mathrm{IS}}\right)$, and determined whether subpopulations departed from HWE (ranging from - 1, more heterozygosity than expected, to 1, less heterozygosity than expected). To measure genetic divergence among subpopulations, Wright's $\mathrm{F}_{\mathrm{ST}}$ was estimated according to F-statistics defined by Weir \& Cockerham [47], whereby

Table 1 nSSR summary information on each locus

\begin{tabular}{|c|c|c|c|c|c|c|c|c|c|}
\hline Locus & Nucleotide repeat & Size (bp) & Primer sequence & $\mathrm{n}_{\mathrm{A}}$ & $\mathrm{T}_{\mathrm{a}}\left({ }^{\circ} \mathrm{C}\right)$ & $\mathrm{Pc}(\mu \mathrm{M})$ & $\mathrm{H}_{\mathrm{O}}$ & $\mathrm{H}_{\mathrm{S}}$ & $p$ \\
\hline \multirow[t]{2}{*}{ Rrms18 } & CATT & $130-143$ & F: GCTITCATTGTTGTACACCTC & 4 & 53 & 3 & 0.171 & 0.488 & $<0.001$ \\
\hline & & & R: ACAAACAGCAATGAGGTACAG & & & & & & \\
\hline \multirow[t]{2}{*}{ Rrms34 } & TGAA & $106-136$ & F: AATAATGTTTCGCACTGAGAG & 11 & 53 & 15 & 0.748 & 0.772 & 0.183 \\
\hline & & & R: CAAGGTAGACCGTTACAGTGA & & & & & & \\
\hline \multirow[t]{2}{*}{ Rrms40 } & CACT & $85-118$ & F: GTAATGGCCATGTCACTAGC & 9 & 53 & 10 & 0.246 & 0.577 & $<0.001$ \\
\hline & & & R: TाTGAGACTCGAAAGAAACAG & & & & & & \\
\hline \multirow[t]{2}{*}{ Rrms44 } & GAGT & $91-98$ & F: CTATGTTGAAAAGGCATCAAT & 3 & 51 & 15 & 0.438 & 0.404 & 0.108 \\
\hline & & & R: GCAAAGTGTTGTTCACTCAAT & & & & & & \\
\hline \multirow[t]{2}{*}{ Rrms72 } & CATT & $128-142$ & F: GAAATGTCAAAGACGAAAGTG & 8 & 51 & 15 & 0.707 & 0.711 & $<0.05$ \\
\hline & & & R: TTGAAGTGCGAAATTAGTCAT & & & & & & \\
\hline \multirow[t]{2}{*}{ Rrms91 } & GAGT & $84-92$ & F: CTATGTTGAAAAGGCATCAAT & 4 & 51 & 5 & 0.587 & 0.625 & $<0.001$ \\
\hline & & & R: GCAAAGTGTTGTTCACTCAAT & & & & & & \\
\hline \multirow[t]{2}{*}{ Rrms03 } & AATA & $147-149$ & F: AACTTGGTCTAAAGTGAAGCA & 2 & 53 & 5 & - & - & - \\
\hline & & & R: TTGAAAAGTCACTAAGCCAAC & & & & & & \\
\hline \multirow[t]{2}{*}{ Rrms23 } & CTCC & $141-142$ & F: CCGTAATGTACGACAAAGTGT & 2 & 53 & 15 & - & - & - \\
\hline & & & R: AAGGTAATCTATCCCCCACT & & & & & & \\
\hline \multirow[t]{2}{*}{ Rrms61 } & CGA & $74-76$ & F: TAAATAGATCGAGACGACCAA & 2 & 53 & 15 & - & - & - \\
\hline & & & R: TCTCTGTGTGAACGATCTGTA & & & & & & \\
\hline
\end{tabular}

Marker names, type of repetitive motif, size range of alleles (bp), primer sequences (forward - $F$, reverse - R), number of alleles $\left(n_{A}\right)$, annealing temperature $\left(T_{a}\right)$, primer concentration used in PCR amplification $(\mathrm{Pc})$, and observed $\left(\mathrm{H}_{\mathrm{O}}\right)$ and expected $\left(\mathrm{H}_{\mathrm{S}}\right)$ heterozygosities, with corresponding $p$-values 
the ratio of heterozygosity within the subpopulation is compared to the total population (ranges from 0 - little to no genetic divergence between populations, to 1 - total divergence between subpopulations).

We also performed an analysis of molecular variance (AMOVA) [48] in GenoDive to test for population genetic structure; calculations were performed on four different hierarchical levels (between environments [rich and poor], between subpopulations [sexes and morphs] within environment, among individuals within subpopulations, and within individuals), and gives us insight in the genetic differentiation between these different levels. Statistical significance was evaluated based on 999 random permutations and distances were calculated using the Infinite Alleles Model.

We further subsampled 30 random individuals per group and performed the same analyses with the aim to control for possible artefacts or bias stemming from missing data or unequal sampling. Random subsampling and reanalysis was performed 5 times (exemplar represented in Additional file 1: Table S2.1-S2.5).

STRUCTURE analysis (GenoDive v2.28 [45]; STRUCTURE add-in [49]) was additioanlly used to infer genetic clustering using the multilocus nSSR data within populations (rich and poor environments) among the respective subpopulations (i.e. females, scramblers and fighters). This analysis used a Monte Carlo Markov Chain (MCMC) to identify genetically distinct clusters by assigning individuals to $\mathrm{K}$ clusters based on assignment probability (Q-value), minimizing departures from HWE and linkage equilibrium. We used a $5 \times 10^{3}$ burn-in, followed by $5 \times$ $10^{4}$ iterations assuming admixture and correlated allele frequencies without prior population information. We ran 1 to $10 \mathrm{~K}$ clusters, with 20 replicates for each cluster. Optimal population clusters were determined according to delta $K$ [50] and bar plot visualisations were compiled using the program STRUCTURE PLOT [51].

\section{Results}

After protocol optimization, we found only 9 of the 16 nSSRs amplified well for our populations, of which 3 loci revealed fixation, and 6 demonstrated both clean/readable peaks and polymorphism across individuals. Thus, these 6 nSSRs were chosen for the genotyping of all remaining individuals.

Across individuals, we had a total of $12.3 \%$ missing or null alleles; $3.6 \%$ in females, $12.8 \%$ in males $(25.9 \%$ in fighters, $3.7 \%$ in scramblers). In the poor environment (19.1\%), missing data for females was $5.4 \%$, and for males, $20.5 \%$ (34.5\% in fighters, and $0.00 \%$ in scramblers). In the rich environment (10.2\%), missing data for females was $8.65 \%$, and for males, $9.68 \%(14.1 \%$ in fighters, and $6.4 \%$ in scramblers). We additionally detected 11 private alleles across 5 loci that differentiated between males and females, and 12 alleles that segregate between the rich (4) or poor (8) environments (Additional file 2: Table S1).

Across all individuals, allelic richness remained low, ranging from 3 to 11 alleles per locus. For four loci, significant deviations from HWE were detected demonstrating an excess of homozygosity present across individuals (Table 1). Deviations from HWE were also detected within our rich and poor environments (Table 2), where rich environments contained significantly lower levels of heterozygosity across all individuals compared to expectation. Poor environments similarly demonstrated lower than expected levels of heterozygosity across all individuals, with the exception of scramblers that were shown to not significantly differ from expectation. These patterns also corresponded to significant levels of inbreeding $\left(\mathrm{G}_{\mathrm{IS}}\right)$, with the exception of scramblers in the poor environment.

Pairwise genetic differentiation between environments (rich and poor) differed significantly $\left(\mathrm{F}_{\mathrm{ST}}=0.109, p<0.001\right)$ between the subpopulations (female, fighter and scrambler) within their respective environments (Table 3), with the exception of scramblers compared to females in the poor environment. Although fighters and scramblers significantly differed from each other within both environments (rich and poor), genetic differentiation was approximately three times lower in the poor environment compared to the rich environment $\left(\mathrm{F}_{\mathrm{ST}}=0.036, p<0.001\right.$, and $\mathrm{F}_{\mathrm{ST}}=0.102, p<0.001$, respectively). These results corroborate the findings that fighters were significantly more genetically divergent compared to scramblers within either environment (Fig. 2).

AMOVA analysis (Table 4) showed significant genetic differentiation across subpopulations (females, fighters, and scramblers; $\mathrm{F}_{\mathrm{SC}}=0.085, p<0.001$ ), between morphs (fighters, and scramblers; $\mathrm{F}_{\mathrm{SC}}=0.073, p<0.001$ ), and between sexes (females, males; $\mathrm{F}_{\mathrm{SC}}=0.069, p<0.001$ ). Subpopulations within environment were also genetically different from one another $\left(\mathrm{F}_{\mathrm{SC}}=0.085, \mathrm{p}<0.001\right)$, but the environments (rich and poor) do not differ from the total population $\left(\mathrm{F}_{\mathrm{CT}}=0.083, p=0.206\right)$.

Table 2 Hardy-Weinberg statistics across environments and subpopulations

\begin{tabular}{llllll}
\hline & Subpopulation & $\mathrm{H}_{\mathrm{O}}$ & $\mathrm{H}_{S}$ & $\mathrm{G}_{\mathrm{S}}$ & $p$ \\
\hline Poor & & 0.487 & 0.578 & 0.158 & $<0.001$ \\
& Females & 0.457 & 0.520 & 0.120 & $<0.05$ \\
& Fighters & 0.390 & 0.566 & 0.311 & $<0.001$ \\
& Scramblers & 0.583 & 0.603 & 0.032 & 0.307 \\
Rich & & 0.398 & 0.600 & 0.336 & $<0.001$ \\
& Females & 0.362 & 0.501 & 0.277 & $<0.001$ \\
& Fighters & 0.329 & 0.581 & 0.436 & $<0.001$ \\
& Scramblers & 0.479 & 0.605 & 0.208 & $<0.001$ \\
\hline
\end{tabular}

Shown are observed $\left(\mathrm{H}_{\mathrm{O}}\right)$ and expected $\left(\mathrm{H}_{\mathrm{S}}\right)$ heterozygosities, inbreeding coefficient $\left(\mathrm{G}_{\mathrm{IS}}\right)$ according to Nei's statistics (1987), and $p$-value 
Table 3 Pairwise $F_{S T}$ values for (sub)population differentiation

\begin{tabular}{lllllll}
\hline & P_F & P_MF & P_MS & R_F & R_MF & R_MS \\
\hline P_F & - & & & & & \\
P_MF & $0.063^{\mathrm{a}}$ & - & & & & \\
P_MS & 0.024 & $0.036^{\mathrm{a}}$ & - & & & \\
R_F & $0.269^{\mathrm{a}}$ & $0.147^{\mathrm{a}}$ & $0.214^{\mathrm{a}}$ & - & & \\
R_MF & $0.085^{\mathrm{a}}$ & $0.103^{\mathrm{a}}$ & $0.109^{\mathrm{a}}$ & $0.213^{\mathrm{a}}$ & - & \\
R_MS & $0.178^{\mathrm{a}}$ & $0.082^{\mathrm{a}}$ & $0.131^{\mathrm{a}}$ & $0.054^{\mathrm{a}}$ & $0.102^{\mathrm{a}}$ & - \\
\hline
\end{tabular}

Shown are the genetic differentiation values per subpopulation: Poor (P), and Rich (R) environments, Female (F), Male Fighter (MF), and Male Scrambler (MS) subpopulations. Significant differences are represented by ${ }^{\mathrm{a}}$ after Bonferroni correction

With the exception of locus Rrms72 demonstrating no significant deviations from HWE (Additional file 1), our subsampled analyses demonstrated near identical results in accordance with our original data set, suggesting any missing/null alleles and unequal sampling within our populations had negligible impact on our results.

Our STRUCTURE analysis demonstrated 2 genetic clusters based on delta $\mathrm{K}$ [50] $(\mathrm{K}=2)$ best fit our data. Genetic clustering similarly illustrated females and scramblers to disproportionately cluster together compared to fighter individuals that formed their own genetic cluster, although this pattern was more stark in rich compared to poor environments (Fig. 3).

\section{Discussion}

Despite previous formative work focusing on sex- and morph-specific population mean transcriptome patterns in $R$. robini $[52,53]$, this study is the first of its kind to quantify individual-level genetic diversity in the bulb mite, building a foundation for further genetic quantification investigations for this microscopic organism. Importantly, due to this individual-level approach, the results from this study demonstrate that ARTs in the bulb mite system are associated with genetic diversity,

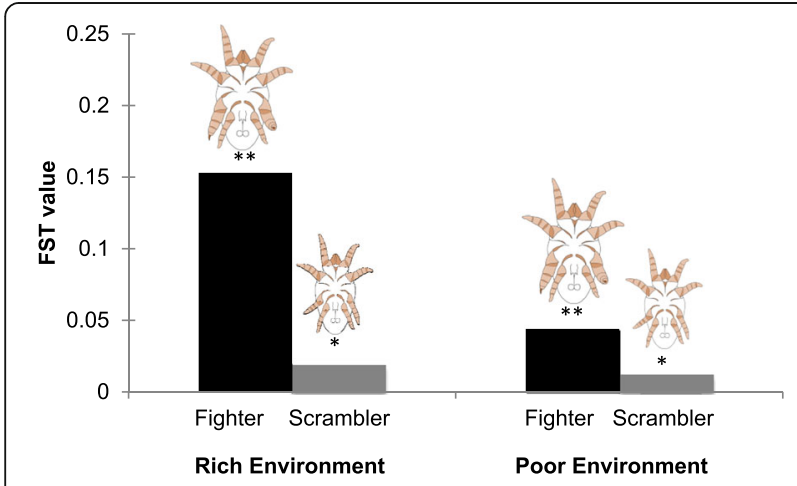

Fig. 2 Genetic differentiation ( $F_{S T}$ ) of male ARTs to the total population within each environment. Significant differences are represented above bars, ${ }^{*} p<0.05,{ }^{* *} p<0.001$. ART images kindly supplied by F.T. Rhebergen which in-turn is further connected with environmental effects (GEIs). The finding that GEIs underlie the pattern of ARTs is likely to have important repercussions to our understanding of selection in this species, and may help to resolve the previous (but confined) observations for genetic (e.g., $[52,53])$ and environmental (e.g., [33, 35, 54]) components operating to mediate male trait expression. GEIs may further help to explain how this polymorphism is maintained within populations over time, notwithstanding often disparate and fluctuating environmental challenges.

\section{GEls, genetic context, and the origin of bulb mite ARTs}

Counter to our hypothesis for genetic diversity-condition links within our male morphs, we find evidence that large fighters are less genetically variable than their smaller scrambler counterparts. As fighters have been shown to achieve higher reproductive success than scramblers [55], while also being capable of killing conspecifics within populations $[56,57]$, it is not entirely surprising that these individuals are less genetically diverse simply as a by-product of effective population size reduction [58], and thus genetic erosion. Indeed, both mating monopolization and increased survival likely combine to effectively limit the genetic pool in ensuing fighter offspring. Alternatively, sex-specific effects of inbreeding depression on fitness are also plausible [59], especially in light of high inbreeding consequences on female bulb mite fecundity in general [31]. Previous studies have proposed that the fitness decline of $R$. robini females derived from fighter selection-lines is evidence for intralocus sexual conflict [60]. Our observations that fighters are more inbred than scrambler males, could equally imply that inbred females are less fit and have a higher probability of being purged within populations, similar to life-span and mortality patterns observed in another invertebrate with sex-specific inbreeding depression [61].

A non-mutually exclusive but more adaptive explanation for the origins of the genetic patterns underlying bulb mite ART expression could be their genetic context, or the relation and interaction of genes underpinning this phenotype (epistasis or genetic correlation). Non-additive, epistatic combinations [62,63] are likely more important than individual genetic components, with pervasive effects from selection to speciation [64]. These genetic interactions have also previously been shown to influence complex traits [65], alter evolutionary trajectories of phenotypes [66], and underlie missing heritability [67].

In the bulb mite specifically, positive epistasis could be responsible for fighter expression, such that many alleles in conjunction work in a way that synergistically outperforms their individual contributions to genetically determine the fighter phenotype. Similarly, if many alleles in coordination lead to a less fit phenotype than expected based on their effects in singularity, the process may give rise to a new/ 
Table 4 Summary of hierarchical AMOVA

\begin{tabular}{|c|c|c|c|c|c|}
\hline Variance component & SD & Variation (\%) & Statistic & F-value & $p$ \\
\hline Between environments & 0.036 & 0.083 & $F_{C T}$ & 0.083 & 0.206 \\
\hline Among subpopulations in environment & 0.038 & 0.078 & $\mathrm{~F}_{\mathrm{SC}}$ & 0.085 & $<0.001$ \\
\hline Among individuals in subpopulation & 0.113 & 0.184 & $F_{I S}$ & 0.219 & $<0.001$ \\
\hline Within individuals & 0.120 & 0.655 & $F_{I T}$ & 0.345 & $<0.001$ \\
\hline
\end{tabular}

AMOVA including standard deviation (jack-knifing over loci), \% of variation, and values of the F-statistic on different levels (between environments, among subpopulation within environment, among individuals within subpopulation, and within individuals), with their corresponding $\mathrm{F}$ and $\mathrm{p}$-values. $\mathrm{F}_{\mathrm{CT}}=$ the proportion of total variance that results from genetic differences among groups, $F_{S C}=$ the proportion of variance among subpopulations within clusters, $F_{I S}=$ the proportion of variance among individuals within subpopulation, $\mathrm{F}_{\mathrm{IT}}=$ the proportion of variance among individuals within the total population

alternative phenotype within a population; certain genetic elements combinations may also mask the effects of others (antagonistic epistasis), functionally suppressing the manifestation of high fitness traits (e.g., [68]). The last two aforementioned processes of negative epistasis could conceivably produce scramblers within our populations.

Correspondingly, genetic correlations among traits could equally link genetic components together causing similar patterns to the ones we see here. ART-specific genetic correlations have been previously shown in another invertebrate taxa [69], and the breakdown of co-adaptive gene-complexes has been implicated in the adoption of a flexible condition-dependent ART [70], together suggesting that genetic context may be a pervasive, important, but under-investigated facet to ART research. Indeed, markedly distinct genetic patterns among ARTs may be expected owing to the correlational selection for various trait optima combinations between morphs. Ultimately, this correlational selection will result in linkage disequilibrium (opposed and eroded by recombination) having far-reaching evolutionary consequences such as the loss of genetic variation, especially for species frequently undergoing genetic drift through founder effects [7].

Insomuch as complex gene-network for traits are presumed ubiquitous [71], and pleiotropic effects in a single locus for systems necessary to support multi-faceted plasticity (e.g., in morphology, physiology, behaviour) seems dubious [7], it's likely that heterozygosity in the bulb mite breaks apart genetic elements that require the coordination for the expression of the fighter phenotype, such as specialized developmental trajectories, large body size, aggression, and weaponry. Accordingly, the threshold for fighter development may require a reduction to heterozygosity, such that when heterozygosity within populations decreases, the threshold for fighter expression concomitantly also decreases. Threshold shifts as a response to ART relative fitness would then reflect cryptic genetic variation underlying the translation of the environmental cue to phenotype in a condition-genotype coupling [27]. Future $R$. robini work should aim to assess whether these same GEI patterns are also reflected in natural populations. However, as these broad GEI associations remain consistent between rearing environments, and our rich environment reflects similar natural history responses to that of natural resources (e.g., garlic bulbs [39]), we have no reason to believe that stock and natural populations would differ in their overall patterns of ART genetic context.

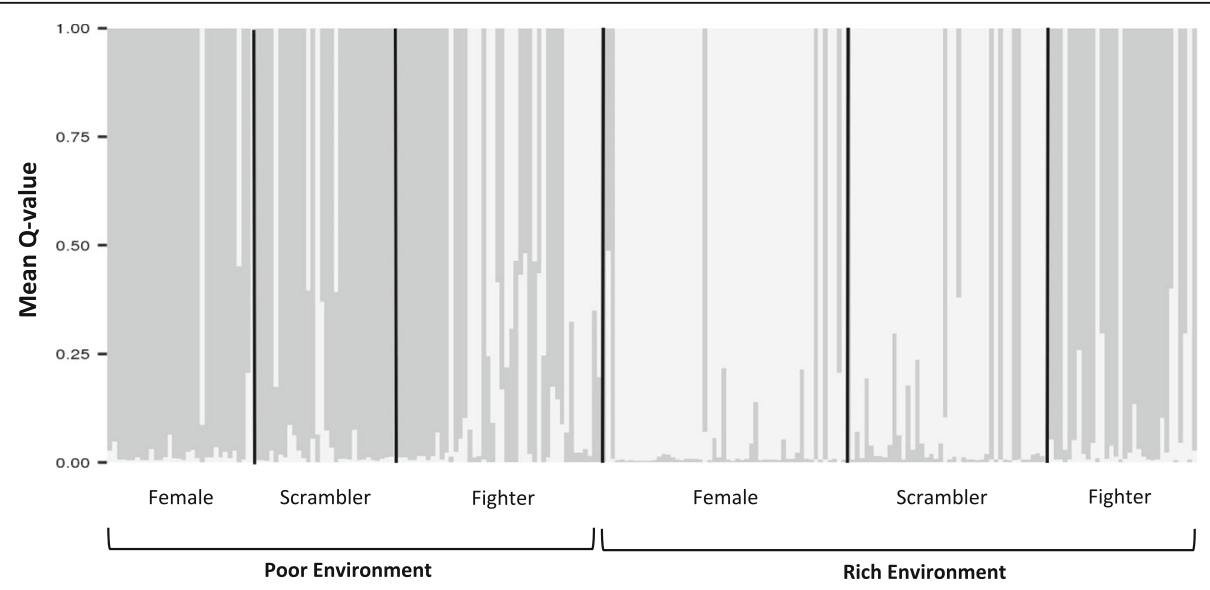

Fig. 3 STRUCTURE plot of subpopulation genetic clusters in different environments. STRUCTURE plot illustrating the mean proportional membership (Q-value) of $R$. robini individuals (females, scramblers, fighters) for $\mathrm{K}=2$ across poor and rich environments 
Population-level diversity and the maintenance of ARTs Considerable variation has been observed in the effects and strength of inbreeding depression among environments, populations of the same species, and even within sexes (e.g., [61, 72-74]). Our study demonstrates that bulb mites generally lack genetic diversity across individuals, but this pattern could stem from a number of scenarios. For example, in our investigation, near even numbers of scramblers, fighters, and females were collected and compared, yet in reality (stock and wild populations), operational sex-ratios are female skewed ([33, 57], pers. observation), and ART frequencies fluctuate within populations based on environmental milieu [54]. In effect, the average genetic contribution of fighters both within poor and rich environments, compared to the combined contribution of scramblers and females, is likely highly over-represented. Moreover, lab reared populations are known to undergo genetic drift and demonstrate lower than average genetic diversity compared to their wild counterparts [75-77]. However, similar to other species [73], bulb mites may also display a general lack of inbreeding consequences. That said, the combined evidence that fighter phenotypes achieve higher reproductive success than scramblers [55], and that bulb mite ARTs demonstrate some level of heritability [35-37] but no frequency-dependence [34, 55], has continuously raised questions as to how these male polymorphisms are sustained within populations. Certainly the added evidence that fighter phenotypes are also associated with excess homozygosity (this study) further complicates our understanding of how male phenotypic and genetic variation are sustained in this system. Here we link the genetic architecture and life-history parameters of ARTs with oscillating environmental conditions, and suggest that these ecological-evolutionary dynamics may hold the answer.

Previous empirical evidence in bulb mites not only demonstrates that scrambler morphs live longer [78], but importantly, that scrambler-selected lines produce more females that lay larger and more eggs over a longer period of time [79], and are generally more fecund than fighter-selected lines [60]. These morph-specific patterns may help to elucidate why we observed the genetic architecture of scramblers and females to be more similar to each other in contrast to fighters, patterns corroborated in gene expression profiles [52]. Similarly, these reproductive patterns may also help explain how fluctuating environmental conditions, and thus the ensuing shifts in ART frequencies, assist in maintaining genetic diversity within this species. For example, individuals that accumulated deleterious mutations otherwise buffered in optimal conditions (e.g., fighters and possibly female offspring of fighters in the bulb mite) would eventually be purged within poor (presumably stressful) environments (e.g., [74]). This mutation-selection balance could also reduce the genetic differentiation between morphs and sexes, as seen in our bulb mite individuals raised in the poor environment. Certainly, genetic variation in the threshold underlying sensitivity to environmental cues, as assumed in the environmental threshold model [21, 22], would thus cause genetic, and therefore concomitant demographic, oscillation within populations, conceivably facilitating stable population persistence even in the face of spatially or temporally unstable environmental challenges.

Across taxa, processes for the maintenance of genetic diversity are especially significant as they serve as a means for populations to adapt to changing environments and thus play an important role for the survival of a species [80], including reducing its vulnerability to ecological challenges such as disease or climate change [81]. Whether ARTs buffer populations from excessive inbreeding, and are more likely to evolve in species that routinely encounter boom-bust cycles or environmental perturbations, is certainly a worthy future investigation.

\section{Conclusion}

The complexity and need for organisms to interact with their environment (to adjust, acclimatize, development, and maximize fitness) implies that genetic context, and thus GEIs, are likely to be pervasive even among plastic phenotypes. Still, the evolution and proximate cause of these phenotypic alternatives are only beginning to be understood. Ultimately, our ability to accurately predict responses to selection based on the genetic variation that maintain thresholds for ARTs, and appreciating the relative genetic and environmental contributions influencing phenotypic expression, is critical to understanding both the breadth and maintenance of within-species variation and a populations capacity to adapt to external adjustments.

\section{Additional files}

Additional file 1: Table S2.1. - S2.5. Exemplar (1 from 5) of subsampled analyses performed from 30 randomly sampled individuals per subpopulation (female, fighter, scrambler) between rich and poor environments. Table S2.1. nSSR information on each locus. Table S2.2. Hardy-Weinberg statistics across environments and subpopulations. Table S2.3. Pairwise FST values for population differentiation. Table S2.4. Summary of hierarchical AMOVA. Table S2.5. Genetic differentiation between strategies (fighters and scramblers) compared to total population within that environment (rich and poor). (DOCX $32 \mathrm{~kb}$ )

Additional file 2: Table S1.1. Allele frequencies by sex, morph, and environments. (DOCX $39 \mathrm{~kb}$ )

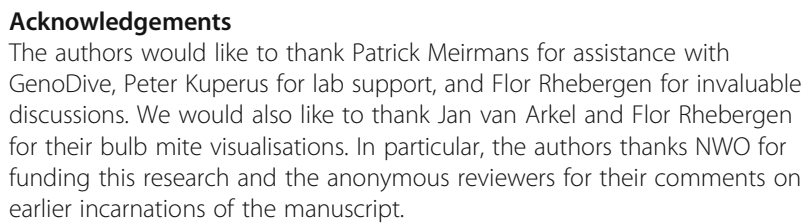


in the design of the study and collection, analysis, and interpretation of data and in writing the manuscript.

\section{Availability of data and materials}

The datasets generated and/or analysed during the current study are available in the Figshare repository, https://doi.org/10.6084/ m9.figshare.7665632 [82].

\section{Authors' contributions}

KAS designed the experiment, MRK designed the primers, and RD performed the genetic amplifications and analysis. All authors contributed to data interpretation. KAS and RD wrote the majority of the manuscript. All authors contributed to the writing of the final version of the manuscript. All authors read and approved the final manuscript.

\section{Ethics approval and consent to participate}

In accordance with the Dutch 2014 Animal Experiments Act (https:// wetten.overheid.nl/BWBR0003081/2014-12-18) (in Dutch), no ethics approval or consent is required for experiments on mites, as regulations within the Act only apply to vertebrates and cephalopods.

\section{Consent for publication}

Not applicable.

\section{Competing interests}

The authors declare that they have no competing interests.

\section{Publisher's Note}

Springer Nature remains neutral with regard to jurisdictional claims in published maps and institutional affiliations.

\section{Author details}

${ }^{1}$ Department of Evolutionary and Population Biology, Institute for Biodiversity and Ecosystem Dynamics, University of Amsterdam, PO Box 94240, 1090 GE Amsterdam, The Netherlands. ${ }^{2}$ Institute of Systematics and Evolution of Animals, Polish Academy of Sciences, Slawkowska 17 St., 31-016 Krakow, Poland.

Received: 22 November 2018 Accepted: 12 February 2019 Published online: 18 February 2019

\section{References}

1. Oliveira RF, Taborsky M, Brockmann HJ. Alternative reproductive tactics. An integrative approach. 1st ed. Cambridge (UK): Cambridge University Press; 2008.

2. Emlen DJ. Environmental control of horn length dimorphism in the beetle Onthophagus acuminatus (Coleoptera: Scarabaeidae). Proc R Soc London Ser B Biol Sci. 1994;256:131-6. https://doi.org/10.1098/rspb.1994.0060.

3. Lank DB, Smith CM, Hanotte O, Burke T, Cooke F. Genetic polymorphism for alternative mating behaviour in lekking male ruff philomachus pugnax. Nature. 1995:378:59-62.

4. Shuster SM, Wade MJ. Equal mating success among male reproductive strategies in a marine isopod. Nature. 1991;350:608-10.

5. Sinervo B, Lively CM. The rock-paper-scissors game and the evolution of alternative male strategies. Nature. 1996;380:240-3.

6. Ocana SW, Meidl P, Bonfils D, Taborsky M. Y-linked Mendelian inheritance of giant and dwarf male morphs in shell-brooding cichlids. Proc R Soc B Biol Sci. 2014;281:20140253. https://doi.org/10.1098/rspb.2014.0253.

7. Neff BD, Svensson El. Polyandry and alternative mating tactics. Philos Trans R Soc B Biol Sci. 2013:368:20120045. https://doi.org/10.1098/rstb.2012.0045.

8. Gillespie JH, Turelli M. Genotype-environment interactions and the maintenance of polygenic variation. Genetics. 1989:121:129-38. https://doi.org/10.1111/jcpp.12441.

9. Rowe $L$, Houle D. The lek paradox and the capture of genetic variance by condition dependent traits. Proc R Soc London Ser B Biol Sci. 1996:263: 1415-21. https://doi.org/10.1098/rspb.1996.0207

10. Markert JA, Grant PR, Grant BR, Keller LF, Coombs JL, Petren K. Neutral locus heterozygosity, inbreeding, and survival in Darwin's ground finches (Geospiza fortis and G. scandens). Heredity. 2004;92:306-15. https://doi.org/10.1038/sj.hdy.6800409.

11. Jensen H, Bremset EM, Ringsby TH, Sæther BE. Multilocus heterozygosity and inbreeding depression in an insular house sparrow metapopulation. Mol Ecol. 2007;16:4066-78. https://doi.org/10.1111/j.1365-294X.2007.03452.x.
12. MacDougall-Shackleton EA, Derryberry EP, Foufopoulos J, Dobson AP, Hahn TP. Parasite-mediated heterozygote advantage in an outbred songbird population. Biol Lett. 2005;1:105-7. https://doi.org/10.1098/rsbl.2004.0264.

13. Vangestel C, Mergeay J, Dawson DA, Vandomme V, Lens L. Developmental stability covaries with genome-wide and single-locus heterozygosity in house sparrows. PLoS One. 2011;6:e21569. https://doi.org/10.1371/journal.pone.0021569.

14. Minias P, Minias A, Dziadek J. Heterozygosity correlates with body size, nest site quality and productivity in a colonial waterbird, the whiskered tern (Chlidonias hybrida, Aves: Sternidae). J Zool Syst Evol Res. 2015;53:133-9.

15. Mitton JB. Theory and data pertinent to the relationship between heterozygosity and fitness. In: The natural history of inbreeding and outbreeding: theoretical and empirical perspectives. Thornhill. Chicago: University of Chicago Press; 1993. p. 17-35.

16. Brown JL. A theory of mate choice based on heterozygosity. Behav Ecol. 1997:8:60-5

17. Watt WB, Carter PA, Donohue K. Females' choice of "good genotypes" as mates is promoted by an insect mating system. Science. 1986;233:1187-90. https://doi.org/10.1126/science.3738528

18. Ferrer ES, García-Navas V, Bueno-Enciso J, Sanz JJ, Ortego J. Multiple sexual ornaments signal heterozygosity in male blue tits. Biol J Linn Soc. 2015;115: 362-75. https://doi.org/10.1111/bij.12513.

19. Kokko H, Heubel K. Condition-dependence, genotype-byenvironment interactions and the lek paradox. Genetica. 2008:134: 55-62. https://doi.org/10.1007/s10709-008-9249-7.

20. Kirkpatrick M, Ryan MJ. The evolution of mating preferences and the paradox of the lek. Nature. 1991;350:33-8.

21. Hazel WN, Smock R, Johnson MD. A polygenic model for the evolution and maintenance of conditional strategies. Proc R Soc B Biol Sci. 1990;242:181-7.

22. Hazel W, Smock R, Lively CM. The ecological genetics of conditional strategies. Am Nat. 2004;163:888-900.

23. Tomkins JL, Hazel W. The status of the conditional evolutionarily stable strategy. Trends Ecol Evol. 2007;22:522-8. https:/doi.org/10.1016/j.tree.2007.09.002.

24. Roff DA. Alternative strategies: the evolution of switch points. Curr Biol. 2011;21:285-7. https://doi.org/10.1016/J.CUB.2011.03.016.

25. Unrug J, Tomkins $J$, Radwan J. Alternative phenotypes and sexual selection: can dichotomous handicaps honestly signal quality? Proc R Soc B Biol Sci. 2004;271:1401-6. https://doi.org/10.1098/rspb.2004.2729.

26. Piché J, Hutchings JA, Blanchard W. Genetic variation in threshold reaction norms for alternative reproductive tactics in male Atlantic salmon, Salmo salar. Proc R Soc B Biol Sci. 2008;275:1571-5. https://doi.org/10.1098/rspb.2008.0251.

27. Buzatto BA, Buoro M, Hazel WN, Tomkins IL. Investigating the genetic architecture of conditional strategies using the environmental threshold model. Proc R Soc B Biol Sci. 2015;282:20152075. https:/doi.org/10.1098/rspb.2015.2075.

28. Deere JA, Coulson T, Smallegange IM. Life history consequences of the facultative expression of a dispersal life stage in the Phoretic bulb mite (Rhizoglyphus robini). PLoS One. 2015;10:e0136872. https:/doi.org/10.1371/journal.pone.0136872.

29. Díaz A, Okabe K, Eckenrode CJ, Villani MG, Oconnor BM. Biology, ecology, and management of the bulb mites of the genus Rhizoglyphus (Acari: Acaridae). Exp Appl Acarol. 2000:24:85-113. https:/doi.org/10.1023/A:1006304300657.

30. Stewart KA, Van den Beuken TPG, Rhebergen FT, Deere JA, Smallegange IM. Evidence for a third male type in a male-dimorphic model species. Ecology. 2018;99:1685-7. https://doi.org/10.1002/ecy.2239.

31. Radwan J. Inbreeding depression in fecundity and inbred line extinction in the bulb mite, Rhizoglyphus robini. Heredity. 2003;90:3716. https://doi.org/10.1038/sj.hdy.6800254

32. Leigh DM, Smallegange IM. Effects of variation in nutrition on male morph development in the bulb mite Rhizoglyphus robini. Exp Appl Acarol. 2014;64: 159-70. https://doi.org/10.1007/s10493-014-9822-y.

33. Smallegange IM, Deere JA. Eco-evolutionary interactions as a consequence of selection on a secondary sexual trait. Adv Ecol Res. 2014;50:145-69. https://doi.org/10.1016/B978-0-12-801374-8.00004-9.

34. Deere JA, Smallegange IM. Does frequency-dependence determine male morph survival in the bulb mite Rhizoglyphus robini? Exp Appl Acarol. 2014; 62:425-36. https://doi.org/10.1007/s10493-013-9751-1.

35. Radwan JW. Male morph determination in two species of acarid mites. Heredity. 1995:74:669-73. https://doi.org/10.1038/hdy.1995.91.

36. Radwan J. Heritability of male morph in the bulb mite, Rhizoglyphus robin (Astigmata, Acaridae). Exp Appl Acarol. 2003;29:109-14. https://doi.org/10. 1023/A:1024260719013.

37. Smallegange IM, Coulson T. The stochastic demography of two coexisting male morphs. Ecology. 2011;92:755-64. https://doi.org/10.1890/09-2069.1. 
38. Smallegange IM. Complex environmental effects on the expression of alternative reproductive phenotypes in the bulb mite. Evol Ecol. 2011;25: 857-73. https://doi.org/10.1007/s10682-010-9446-6.

39. Gerson U, Capua S, Thorens D. Life history and life tables of Rhizoglyphus robini Claparede (Acari: Astigmata: Acaridae). Acarologia. 1983;24:439-48.

40. Gerson U, Cohen E, Capua S. Bulb mite, Rhizoglyphus robini (Astigmata: Acaridae) as an experimental animal. Exp Appl Acarol. 1991;12:103-10. https://doi.org/10.1007/BF01204403.

41. Radwan J. Male morph determination in Rhizoglyphus echinopus (Acaridae) Exp Appl Acarol. 2001:25:143-9. https://doi.org/10.1023/A:1010688516704.

42. Hale ML, Burg TM, Steeves TE. Sampling for microsatellite-based population genetic studies: 25 to 30 individuals per population is enough to accurately estimate allele frequencies. PLoS One. 2012;7: e45170. https://doi.org/10.1371/journal.pone.0045170.

43. Knegt B, Potter T, Pearson NA, Sato Y, Staudacher H, Schimmel BC, et al. Detection of genetic incompatibilities in non-model systems using simple genetic markers: hybrid breakdown in the haplodiploid spider mite Tetranychus evansi. Heredity. 2017;118:311-21. https:/doi.org/10.1038/hdy.2016.103.

44. Kolasa M. Markery mikrosatelitarne i zmienność genetyczna rozkruszka hiacyntowego (Rhizoglyphus robini). Jagiellonian University, Biology department; 2015.

45. Meirmans PG, Van Tienderen PH. GENOTYPE and GENODIVE: two programs for the analysis of genetic diversity of asexual organisms. Mol Ecol Notes. 2004;4:792-4. https://doi.org/10.1111/j.1471-8286.2004.00770.x.

46. Nei M. Estimation of average heterozygosity and genetic distance from a small number of individuals. Genetics. 1978;89:583-90. https://doi.org/10.3390/ijms15010277.

47. Weir BS, Cockerham CC. Estimating F-statistics for the analysis of population structure. Evolution. 1984;38:1358-70. https://doi.org/10.2307/2408641.

48. Excoffier L, Smouse PE, Quattro JM. Analysis of molecular variance inferred from metric distances among DNA haplotypes: application to human mitochondrial dna restriction data. Genetics. 1992;131:479-91. https://doi.org/10.1007/s00424-009-0730-7.

49. Pritchard JK, Stephens M, Donnelly P. Inference of population structure using multilocus genotype data. Genetics. 2000;155:945-9.

50. Evanno $G$, Sebastien $R$, Jérôme $G$. Detecting the number of clusters of individuals using the software STRUCTURE: a simulation study. Mol Ecol. 2005;14:2611-20.

51. Ramasamy RK, Ramasamy S, Bindroo BB, Naik VG. STRUCTURE PLOT: a program for drawing elegant STRUCTURE bar plots in user friendly interface. Springerplus. 2014;3: 431. https://doi.org/10.1186/2193-1801-3-431 eCollection 2014.

52. Stuglik MT, Babik W, Prokop Z, Radwan J. Alternative reproductive tactics and sex-biased gene expression: the study of the bulb mite transcriptome. Ecol Evol. 2014:4:623-32. https://doi.org/10.1002/ece3.965.

53. Joag R, Stuglik M, Konczal M, Plesnar-Bielak A, Skrzynecka A, Babik W, et al. Transcriptomics of intralocus sexual conflict: gene expression patterns in females change in response to selection onamale secondary sexual trait in the bulb mite. Genome Biol Evol. 2016;8:2351-7. https://doi.org/10.1093/gbe/ew169.

54. Smallegange IM, Thorne N, Charalambous M. Fitness trade-offs and the maintenance of alternative male morphs in the bulb mite (Rhizoglyphus robini). J Evol Biol. 2012;25:972-80. https://doi.org/10.1111/j.1420-9101.2012.02490.x.

55. Radwan J, Klimas M. Male dimorphism in the bulb mite, rhizoglyphus robini: fighters survive better. Ethol Ecol Evol. 2001;12: 69-79. https://doi.org/10.1080/08927014.2001.9522788.

56. Radwan J, Czyż M, Konior M, Kołodziejczyk M. Aggressiveness in two male morphs of the bulb mite Rhizoglyphus robini. Ethology. 2000;106:53-62.

57. Smallegange IM, Fernandes RE, Croll JC. Population consequences of individual heterogeneity in life histories: overcompensation in response to harvesting of alternative reproductive tactics. Oikos. 2018:127:738-49.

58. Reed DH, Frankham R. Correlation between fitness and genetic diversity. Conserv Biol. 2003:17:230-7.

59. Ebel ER, Phillips PC. Intrinsic differences between males and females determine sex-specific consequences of inbreeding. BMC Evol Biol. 2016;16: 36. https://doi.org/10.1186/s12862-016-0604-5.

60. Plesnar Bielak A, Skrzynecka AM, Miler K, Radwan J. Selection for alternative male reproductive tactics alters intralocus sexual conflict. Evolution. 2014;68: 2137-44. https://doi.org/10.1111/evo.12409.

61. Fox CW, Scheibly KL, Wallin WG, Hitchcock LJ, Stillwell RC, Smith BP. The genetic architecture of life span and mortality rates: gender and species differences in inbreeding load of two seed-feeding beetles. Genetics. 2006; 174:763-73. https://doi.org/10.1534/genetics.106.060392.
62. Bateson W. Mendel's principles of heredity. Cambridge (UK): Cambridge University Press; 1909.

63. Fisher RA. The correlation between relatives on the supposition of Mendelian inheritance. Trans R Soc Edinburgh. 1918;52:399-433.

64. Wade MJ. A gene's eye view of epistasis, selection and speciation. J Evol Biol. 2002;15:337-46.

65. Wei WH, Hemani G, Haley CS. Detecting epistasis in human complex traits Nat Rev Genet. 2014;15:722-33. https://doi.org/10.1038/nrg3747.

66. Hill WG, Goddard ME, Visscher PM. Data and theory point to mainly additive genetic variance for complex traits. PLoS Genet. 2008;4: e1000008. https://doi.org/10.1371/journal.pgen.1000008.

67. Zuk O, Hechter E, Sunyaev SR, Lander ES. The mystery of missing heritability: genetic interactions create phantom heritability. Proc Natl Acad Sci. 2012; 109:1193-8. https://doi.org/10.1073/pnas.1119675109.

68. Agrawal AF, Whitlock MC. Environmental duress and epistasis: how does stress affect the strength of selection on new mutations? Trends Ecol Evol. 2010;25:450-8. https://doi.org/10.1016/J.TREE.2010.05.003.

69. Abbott JK, Svensson El. Morph-specific variation in intersexual genetic correlations in an intra-specific mimicry system. Evol Ecol Res. 2010:105-18.

70. Stewart KA, Hudson CM, Lougheed SC. Can alternative mating tactics facilitate introgression across a hybrid zone by circumventing female choice? J Evol Biol. 2017:30:412-21. https://doi.org/10.1111/jeb.13017.

71. Weinreich DM, Lan Y, Wylie CS, Heckendorn RB. Should evolutionary geneticists worry about higher-order epistasis? Curr Opin Genet Dev. 2013; 23:700-7. https://doi.org/10.1016/J.GDE.2013.10.007.

72. Fowler $\mathrm{K}$, Whitlock MC. The variance in inbreeding depression and the recovery of fitness in bottlenecked populations. Proc R Soc B Biol Sci. 1999; 266:2061-6. https://doi.org/10.1098/rspb.1999.0887.

73. Armbruster $P$, Armbruster $P$, Reed $D H$. Inbreeding depression in benign and stressful environments. Heredity. 2005;95:235-42. https:/doi.org/10.1038/sj.hdy.6800721.

74. Enders LS, Nunney L. Seasonal stress drives predictable changes in inbreeding depression in field-tested captive populations of Drosophila melanogaster. Proc R Soc London B Biol Sci. 2012;279: 3756-64. https://doi.org/10.1098/rspb.2012.1018.

75. Kawecki TJ, Lenski RE, Ebert D, Hollis B, Olivieri I, Whitlock MC. Experimental evolution. Trends Ecol Evol. 2012;27:547-60. https:/doi.org/10.1016/j.tree.2012.06.001.

76. Slade B, Parrott ML, Paproth A, Magrath MJL, Gillespie GR, Jessop TS. Assortative mating among animals of captive and wild origin following experimental conservation releases. Biol Lett. 2014;10: 20140656. https://doi.org/10.1098/rsbl.2014.0656.

77. Lainhart W, Bickersmith SA, Moreno M, Rios CT, Vinetz JM, Conn JE. Changes in genetic diversity from field to laboratory during colonization of anopheles darlingi root (Diptera: Culicidae). Am J Trop Med Hyg. 2015;93: 998-1001. https://doi.org/10.4269/ajtmh.15-0336.

78. Plesnar-Bielak A, Skwierzyńska AM, Hlebowicz K, Radwan J. Relative costs and benefits of alternative reproductive phenotypes at different temperatures - genotype-by-environment interactions in a sexually selected trait. BMC Evol Biol. 2018;18. https://doi.org/10.1186/s12862-018-1226-x.

79. Van den Beuken TPG, Smallegange IM. Life-history consequences of bidirectional selection for male morph in a male-dimorphic bulb mite. Exp Appl Acarol. 2018:1-18. https://doi.org/10.1007/s10493-018-0320-5.

80. Frankham R. Genetics and extinction. Biol Conserv. 2005;126:131-40. https://doi.org/10.1016/j.biocon.2005.05.002.

81. King K, Lively C. Does genetic diversity limit disease spread in natural host populations? Heredity. 2012;109:199-203. https:/doi.org/10.1038/hdy.2012.33.

82. Stewart SK, Draaijer R, Kolasa MR, Smallegange IM. The role of genetic diversity in the evolution and maintenance of environmentally-cued, male alternative reproductive tactics: datasets. figshare, 2019. https://doi.org/10.6084/m9.figshare.7665632 